\title{
MATERNO-FETAL IMMUNOTOLERANCE: AN EVOLUTIONARY VIEW
}

\section{Luana Paulesu}

\section{Department of Life Sciences, University of Siena}

\begin{abstract}
Since Medawar (1953), much attention has been given to the immunological paradox of the survival and growth of the semi-allogeneic fetus in the maternal uterus. Numerous studies, mainly on the human placenta, have established fundamental mechanisms of this phenomenon; however, many aspects are still unclear and the complex process has yet to be completely defined. One of the accepted principles is that the secretion and action of mediators, i.e. cytokines, at the maternofetal interface have a central role. Focusing on the cytokine Interleukin-1 (IL-1) the review highlights the importance of a physiological approach based on evolutionary studies in animals using similar or different reproductive strategies. Data on IL-1 in viviparity and oviparity, two reproductive strategies in which female reproductive tissues have to deal with paternalderived antigens on sperm, fertilized eggs, and embryo, will be presented and discussed in the light of materno-fetal immuntolerance. Ovuliparity, a reproductive modality in which the eggs are released from the female reproductive tract and fertilization and embryonic development take place in the external environment will also be extensively reported as a negative control in the studies on materno-fetal immunotolerance.

The evidence shown reveals that non-mammalian vertebrates with different reproductive strategies represent a good model to understand biological mechanisms allowing fetal acceptance and growth in the maternal tissues.
\end{abstract}

Key words: pain, sex.

\section{THE MATERNO-FETAL IMMUNOTOLERANCE}

Retention of the embryo within the maternal reproductive tissues (viparity) has many evolutionary advantages but implies the coexistence of the semi-allogeneic foetus with the mother for the duration of pregnancy. The zygote, the first cell of the new individual is in fact formed by the union of the male (sperm) and the female (ovum) gametes and is therefore contains DNA derived from both parents (Figure 1). This might cause a complex conflict between the mother's own genes and those of the paternal ones representing a great risk for the embryo which could be rejected and thus not reach complete maturation [1].

It was Sir Peter Medawar in the far 1953 [2] in his lecture at the conference of the Society for Experimental Biology, which was held in Oxford back in 1953, that first brought to attention of scientists some immunological problems raised with the evolution of Viviparity. He defined, the relationship between the pregnant mother and her antigenically foreign fetus as an immunological paradox [3]. Despite the antigenic

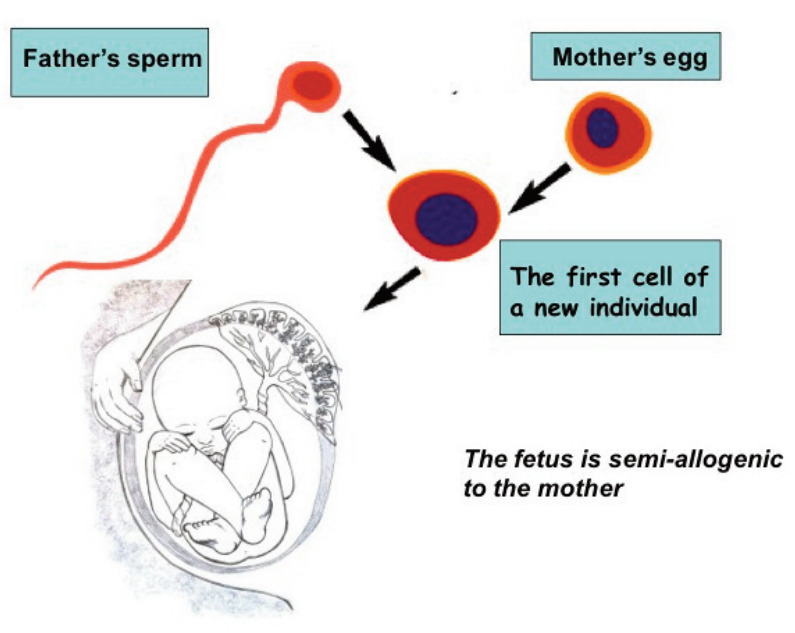

Figure 1. The zygote, the first cell of a new individual, is formed by the union of a paternal sperm and a maternal egg. The fetus is semi-allogenic to the mother. 
dissimilarities between mother and foetus, the conceptus is in fact not rejected. The fetus grows undisturbed in the mother's womb until its complete development.

Viviparity is not a unique characteristic of mammals but is also present in many species of other vertebrate groups (reptiles, amphibians, fishes) (Table 1). Although the acquisition of this reproductive strategy has the advantage to protect the fetus from the external environment, the viviparous species have to develop immunological mechanisms to prevent rejection of the semi-allogeneic embryo by the mother [4].

\section{THE PLACENTA IS AN IMMUNOLOGICALLY ACTIVE SITE}

Viviparity may involve the formation of a placenta, a structure formed by the apposition of fetal extra-embryonic membranes and maternal tissues [5]. It is at the level of the placenta, and fetal membranes, that tissues contact between the fetal graft and the maternal host is made [6]. The placenta is therefore the truly materno-fetal interface, the organ in which immunological mechanisms have to develop to prevent rejection of the embryo by the mother.

Different types of placenta can be distinguished depending on the relationship between fetal membranes and maternal tissues (Figure 2). In the epithelio-chorial type, fetal membranes are only juxtapposed to the uterine lining with no invasiveness. This type of placenta is present in some species of mammals including pigs, horses, cows and sheep [7]. It is also present in some species of squamate reptiles and elasmobranch fishes [8-10]. In other species of mammals, fetal membranes can penetrate the uterus up to the endothelium

Table 1. Viviparity in vertebrates.

\begin{tabular}{cc}
\hline MAMMALS & Marsupials, Eutherians \\
\hline BIRDS & ----- \\
\hline REPTILES & Numerous families of squamate reptiles \\
\hline AMPHIBIANS & Urodels \\
\hline FISHES & Elamobranchs \\
\hline
\end{tabular}

\section{Relationships of the fetal membranes to maternal tissues}

\section{Types of \\ placenta}

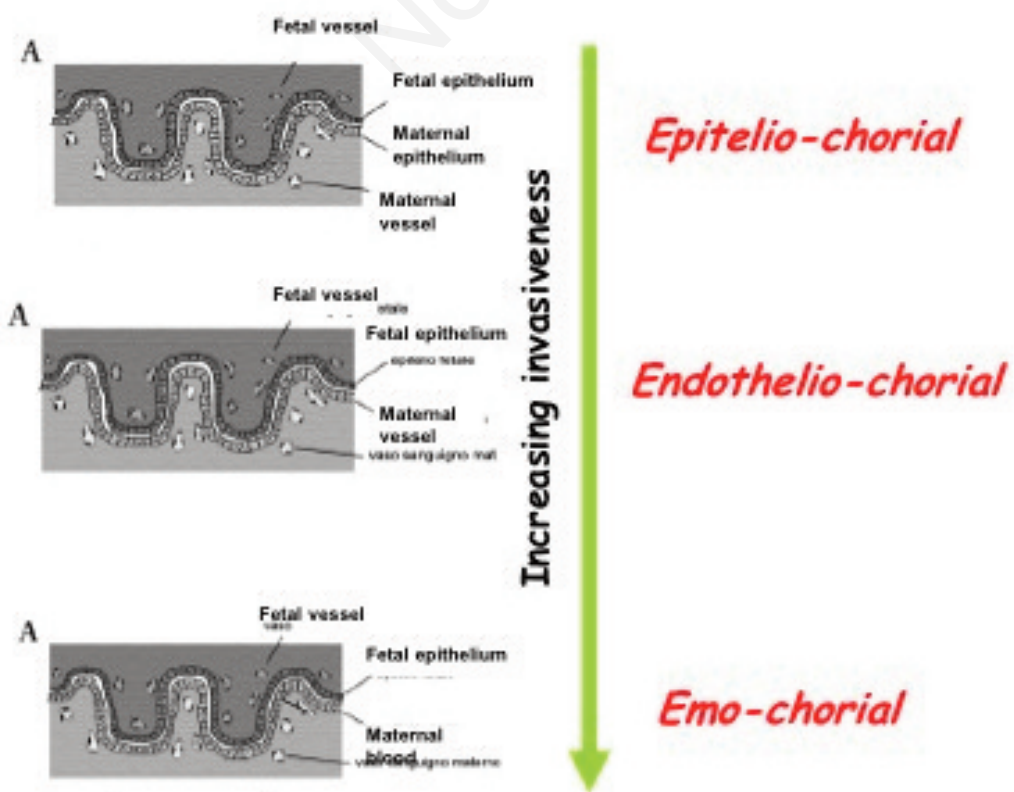

(Pig, Horse, Cow, Sheep, Squamate reptiles, Elasmobranch fishes)

(Elephant, Carnivors)

(Humans, Primates, Rodents)

Figure 2. Types of placenta present in mammalian and non-mammalian vertebrates. 
of maternal vessels (endothelio-chorial placenta) or to the maternal blood (hemo-chorial placenta) [11-12]. The most invasive hemo-chorial type of placenta is present in humans, primates and rodents. In this type of placenta, the chorion destroys the vasal endothelium and is in direct contact with the maternal blood. While this type of placenta is the most advantageous in terms of the transfer of nutrients from the mother to the fetus, it is at higher risk of immunological attack because of the direct contact of fetal chorion with the maternal immune cells. For obvious reasons, the human hemo-chorial placenta is the most studied. Much knowledge on this type of placenta has also been obtained studying in mice, the animal species most used in the laboratories.

\section{IMMUNE FEATURES AT THE HUMAN MATERNO-FETAL INTERFACE}

Besides having defined the relationship between the pregnant mother and her antigenically foreign fetus as an immunological paradox, Medawar offered some possible solutions to the problem. He proposed that: "The reasons why the foetus does not habitually provoke an immunological reaction from his mother may be classified under three headings: (a) the anatomical separation of foetus from mother; (b) the antigenic immaturity of the foetus; and (c) the immunological indolence or inertness of the mother".

Although evidence obtained in the fifty years following Medawar's postulates revealed that none of his postulates provide a complete explanation, Medawar is considered as the founding father of the Reproductive Immunology, the science that deals with the immunological mechanisms that allow fetal survival and growth in the maternal uterus. Medawar's postulates provided in fact the framework for scientific research on this topic from the 50s to the present day [2].

\section{The placenta as an anatomical barrier}

The human placenta is divided into functional units called cotyledons. Within the cotyledon, the chorionic villi, form trees with numerous branches and subbranches terminating in villous blunt-endings. These villi, named "floating villi" directly contact the maternal blood that flows in the relatively open intervillous space where they are embedded (Figure 3). A layer of trophoblast cells forms the interface between the maternal blood and fetal tissues. This interface consisting of a syncytium of multinucleated and differentiated trophoblast cells (syncytiotrophoblast) forms the placental barrier between maternal and fetal circulation. In the first trimester, there is also a layer of proliferative mononuclear trophoblast cells (cytotrophoblast) beneath the syncytiotrophoblasts [13].

The placental barrier separates the maternal from the fetal circulation preventing maternal cell traffic into the fetus. However in human pregnancy, the constant turnover of villous trophoblast results in extrusion of apoptotic material into the maternal circulation. This material is commonly referred to as "fetal", but is actually derived from the placenta [14]. Furthermore, in a minority of villi (anchoring villi) trophoblast cells overcome the epithelial layer and form cell columns that fix the villi to the maternal tissue. Then these cells move deeper into the maternal tissues up to the spiral arteries (Figure 3).

Therefore, in spite of the anatomical separation of fetal and maternal circulation, there are, in the placenta, intimate contact surfaces between trophoblast and maternal immune cells. These are a) the villous trophoblast that is in direct contact with maternal blood in the intervillous space; b) the extra-villous trophoblast that is in contact with maternal immune cells both in the tissue and in the maternal blood.

The immunological mechanisms put in place either on one side or the other of the materno-fetal interface will be reported in the following paragraphs starting from the postulates of Medawar.

\section{Trophoblast antigenicity}

Medawar hypothesized that the trophoblast could not endure the rejection by the mother because of its immunological immaturity. Studies have shown that that human trophoblast is characterized by the lack of the highly polymorphic classical MHC class II and class I antigens, human leukocyte antigen (HLA)-A and HLA-B [15]. It however expresses a combination

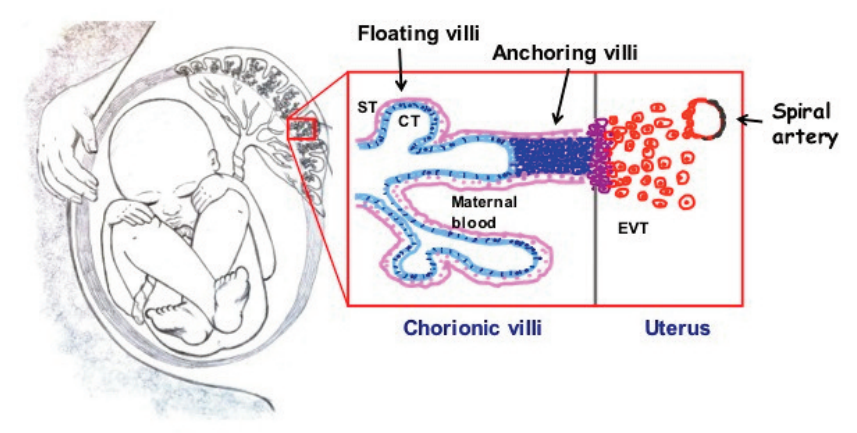

Figure 3. A schematic illustration of human placenta with cotyledons. In the right panel is illustrated differentiation in floating villi and anchoring villi. Cytotrophoblast cells (CT) within the placental villi serve as progenitors of all the differentiated trophoblast cell populations including the syncytiotrophoblast (ST) of the floating villi and the extravillous trophoblast (EVT) of the anchoring villi. The ST provide the physical barrier preventing maternal cell traffic into the fetus. The EVT of the anchoring villi migrate into the stroma of the decidua up to the spiral arteries thus coming in contact with maternal cells both in the tissue and in the blood. 
of classical HLA-C and non classical HLA-G and HLA$\mathrm{E}$ thus displaying a highly unusual surface antigen repertoire [16]. Since non-classical MHC class I molecules exhibit extremely limited polymorphisms they do not elicit a prominent immune response [17]. Moreover, even though the specific roles of HLA-G and -E are not fully defined, their unusual properties seem to contribute to a toleragenic rather than an immunogenic phenotype during early pregnancy by downregulating maternal allogeneic responses locally in the uterus $[16,18,19]$.

These evidences clearly indicate that despite exhibiting reduced antigenicity fetal trophoblast does not hide its diversity. It reveals itself but showing its features less aggressive.

\section{Maternal immunocompetence}

Unlike Medawar's postulates that evoked the mother's immunological inertness as a cause of nonrejection of the fetus, the mother is not immunesuppressed during pregnancy, a condition that could indeed be harmful to her health, making it more susceptible to disease. The mother recognizes and reacts to the semi-allogeneic fetus "the foreigner". Her response is beneficial thanks to a unique population of immune cells in the decidua.

Already in the secretory phase of the cycle and to a greater extent after the implantation of the blastocyst, the uterus is increasing the number of a population of NK cells. These cells differ from the peripheral NK cells in genotype, phenotype and functionality, and are therefore characterized as uterine NK (uNK) cells. uNK cells display the potential capacity to interact with the fetal counterpart as they express receptors for nonclassical MHC class I molecules HLA-E and HLA-G expressed by trophoblast [20-22]. T regulatory (Treg) cells also abandon in the decidua in early pregnancy [23-25]. Treg deficiency is associated with early spontaneous abortion in animal models $[26,27]$ and low Treg levels are associated with recurrent miscarriage in humans [28]. Although the specific function of Treg cells during implantation has not been elucidated, these cells play a critical role in maintaining tolerance to paternal-derived antigens expressed by the developing fetus [29].

All together, the studies carried out on the basis of the Medawar's postulates have confirmed that both parties involved, trophoblast and uterus, contribute to the survival and growth of the fetus in the womb of the mother. However, unlike from what it was postulated, the two parties recognize each other and interact. It is currently known that the recognition and interaction of fetal trophoblast by maternal immune cells occur in normal pregnancy and play a crucial role for the success of reproduction [30]. Indeed this particular relationship between the maternal and fetal tissues causes the secretion of soluble molecules which acting on one and/or the other side, provide beneficial effect for fetal survival and growth as well as pregnancy health [31, 32].

I will now focus on the molecules at the maternofetal interface trying to summarize the concepts that make these molecules critical mediators of maternofetal immunotolerance. Moreover I will report data on the presence of some of these molecules at the maternofetal interface in various vertebrates and discuss these data with regard to the importance of these molecules in the development of viviparity.

\section{THE FETO-MATERNAL MOLECULAR DIALOGUE}

A complex of soluble molecules is produced by different cell types in both the fetal and maternal tissues and acts on these tissues contributing to the activation and coordination of the series of events necessary for successful pregnancy [31, 32]. Thus, mother and embryo interact via specific tissues (trophoblast and uterus) in a reciprocal exchange of molecules that act as communication signals. This interactive relationship between the embryo and the mother has the characteristics of a true dialogue (fetomaternal dialogue): a dialogue that uses molecules instead of words (Figure 4).

The feto-maternal dialogue begins in very early pregnancy, before implantation in the uterus. The embryo, still in the state of unformed cell mass, produces some "signals" which act on the mother to create a uterine environment favourable to its implantation $[33,34]$.

Human chorionic gonadotropin (hCG) is the first known hormonal signal in human pregnancy [35]. Its measurement in the maternal blood and urine is not only diagnostic but also has good predictive value for pregnancy outcome both in normal and in in vitro fertilization (IVF) pregnancies [36, 37]. The feto-maternal dialogue becomes more intense when the trophoblast, the outer layer of the blastocyst, comes into contact with the uterine wall and invades it [38]. Molecules with autocrine/paracrine action (cytokines) play a critical role in pregnancy [39]. Since they are potent immunoregulators, cytokines play a key role in the maternal tolerance to the semi-allogeneic embryo [34]. They are also mediators of cell proliferation/differentiation and apoptosis contributing to fetal growth and expansion in the maternal tissues $[39,40]$. Therefore, their presence at the materno-fetal interface may modulate the maternal immune response and contribute to the expansion of fetal tissues in the maternal uterus $[41,42]$. In the last three decades, virtually all known cytokines have been found at the materno-fetal interface, mainly in humans and mice [34, 43]. These include interferons (IFNs), interleukins (ILs), leukemia inhibitory factor (LIF), tumor necrosis factors (TNFs), 
transforming growth factors (TGFs), colony stimulating factors (CSFs), vascular endothelial growth factors (VEGFs) and many others (Fig.4). The action of these molecules is expressed in a network in which cytokines can induce or inhibit each other (Figure 4). They may act either in concert, or in sequence, first one or a group and then another or another group as it will be better described in the following chapter.

\section{ROLE OF CYTOKINES IN PREGNANCY}

Despite the great progress of knowledge in the last two decades, the specific role of cytokines at the materno-fetal interface still remains unclear and much work remains to be done.

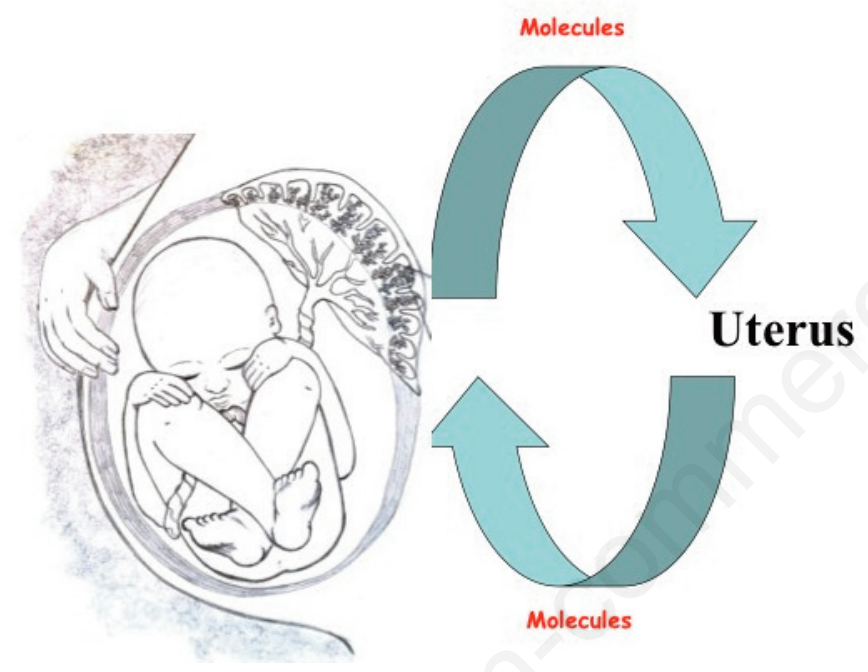

Figure 4. Mother and embryo interact in a reciprocal exchange of molecules forming a true dialogue.

\section{Th1}

Pro-inflammatory cytokines
A balance among different cytokines is believed to be fundamental for the success of reproductive processes. In this context, an important theory proposed by Wegmann hypothesizes a prevalence of Th2 cytokines (IL-4, IL-5, IL-10), whose immunity is of the humoral type, rather than Thl cytokines (TNF $\alpha$, IFN $\gamma$, IL-2), whose immunity is of the cytotoxic type [44]. This theory defines Th2 cytokines as "beneficial" and Thl cytokines as "bad" for pregnancy.

Yet, although still receiving much attention, the Th1/Th2 cytokine dichotomy now appears too simplistic [45]. It considers pregnancy a single event while it is now currently recognized that pregnancy is characterized by three distinct biological phases, each one characterized by different pools of cytokines. Moreover, the balance between pro-inflammatory and anti-inflammatory cytokines overlaps with that of Th1/Th2 [46-48]:

In brief, the early phase of pregnancy, corresponding to blastocyst implantation and placental development, is characterized by an inflammatory environment with an increase of Thl/pro-inflammatory cytokines. The second phase of pregnancy corresponding to the maintenance of pregnancy, is characterized by an antiinflammatory state with the predominance of Th2/antiinflammatory cytokines. This phase which begins as soon as pregnancy is established and lasts almost up to the term, allows uterine quiescence and fetal growth and development. In the third phase, near term, a new increase of Thl/pro-inflammatory cytokines plays a fundamental role in uterine contraction and cervical dilatation.

In summary, pregnancy is based on an evolving balance of cytokines which undergoes changes in the cytokine type or concentration at different phases of pregnancy (Fig.5).

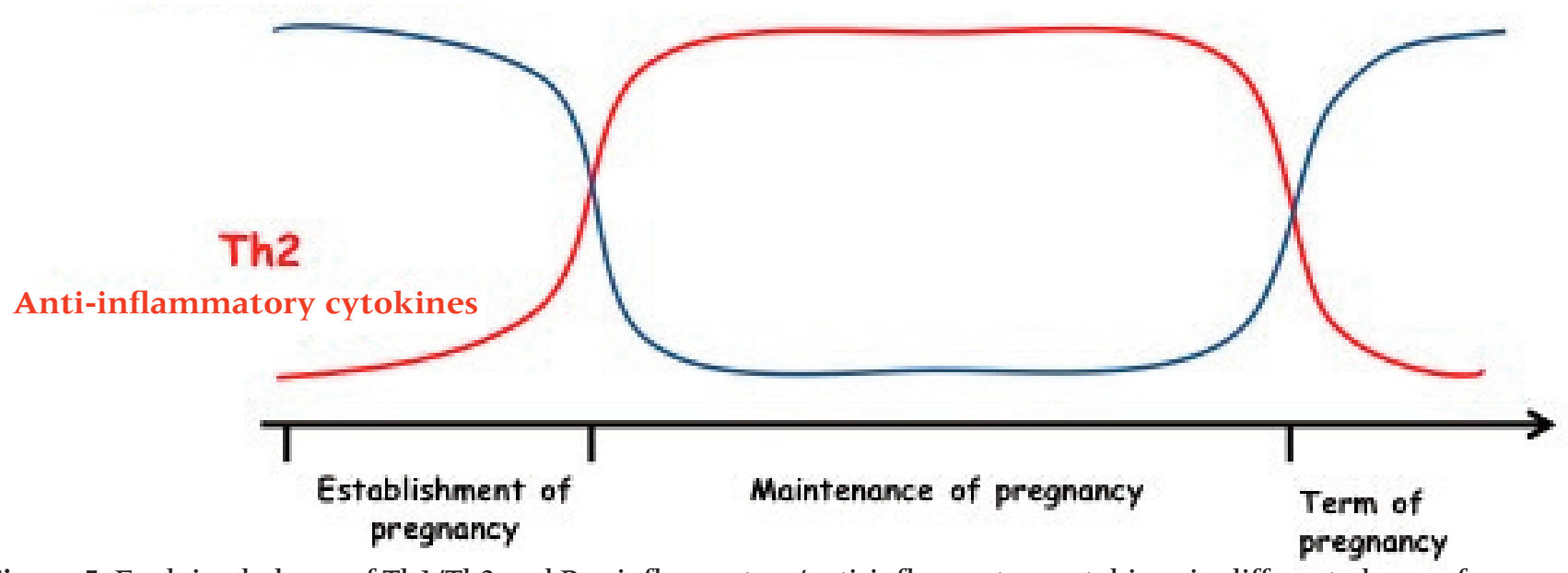

Figure 5. Evolving balance of Th1/Th2 and Pro-inflammatory/anti-inflammatory cytokines in different phases of pregnancy. 
Important studies on cytokines in pregnancy have been conducted on mice, offering the possibility of animals with specific cytokine gene deletions. These studies have shown that only three (LIF, IL-6, IL-11) of the cytokines present at the materno-fetal interface are unequivocally required for implantation in mice [49-51].

However, as specific reproductive processes in pregnancy, e.g. implantation, maintenance of pregnancy and parturition, are characterized by a balance of cytokines with agonistic or antagonistic effects, it appears to be logical that a lack of specific cytokines may activate alternative pathways involving the secretion and action of other cytokines with a similar role. LIF, IL-6 and IL-11 are members of the same cytokine family sharing an accessory signal transducing glycoprotein (gp) 130 through separate receptor subunits [52]. Therefore, depletion of either one cytokine may not be sufficient to reveal the specific role of this molecule in reproduction.

We think that analysis of cytokines in an intact organ preserving tissue homeostasis could help identify the real situation. In this context, a physiological approach, performed in the last 15 years $[53,54]$, is based on evolutionary studies in animals using similar or different reproductive strategies including, viviparity, with or without formation of placental structures, and oviparity, with or without egg/embryo retention. In all these reproductive strategies, maternal reproductive tissues have to deal with paternal-derived antigens on sperm, fertilized eggs, and embryo. Cytokines are mediators of the innate immune response, an ancient immunological system which can be found throughout vertebrates up to mammals. It can be assumed that these molecules might have played a role in the maternal immunotolerance from the simplest forms.

\section{INTERLEUKIN-1, A CYTOKINE FAMILY WITH HIGHLY CONSERVATIVE PROPERTIES AND IMPORTANT ROLES IN MAMMALIAN REPRODUCTION}

Studies of the IL-1 family in vertebrates with different reproductive strategies are possible because of the highly conservative properties of its components, IL$1 \beta$ and its functional membrane receptor IL-1R tI. Cloning of IL-1 $\beta$ has been performed in different classes of vertebrates including mammals, birds, amphibians and fishes [55]. IL-1 signaling system is also evolutionarily conserved as the intracytoplasmic region of IL-1R shows strong sequence similarities with the corresponding region of Toll-like receptors (TLRs) identified in mammals and other vertebrates (fishes, amphibians, birds) [56-58]. This region, homologous to the cytoplasmic region of Drosophila Toll protein which mediates embryo dorso-ventral polarity, also plays an important role in triggering defensive reactions against microbial infections in both Drosophila and mammals [59-61]. On these bases, binding of IL-1 to its receptor produces signals of the body's response to microbial invasion from insects to mammals [62].

Studies performed in humans and mice have shown that the IL-1 plays important roles in uterine receptivity and embryo implantation. The first evidences obtained in both humans and mice date back to the early 90 s (Table 2 ). It was shown that IL- 1 family components were present in the endometrium with maximal expression in the period of blastocyst implantation $[63,64]$. IL- 1 is also expressed in the fetal counterpart in early pregnancy both in humans and mice suggesting its potential role in the cross-talk between embryo and endometrium $[65,66]$. IL- $1 \beta$ is able to act in fact in the syncytio-trophoblast by inducing hCG release [67] and in the human endometrium by stimulating the secretion of different cytokines (IL-6, IL-8, LIF and

Table 2. The first evidences on IL-1 in pregnancy establishment.

\section{Studies in humans}

$>\quad$ IL-1 $\beta$ and IL-1R tI are present in the endometrium with a peak in the secretory phase $[63,64]$

$>$ IL- $1 \alpha$ e IL- $1 \beta$ is present in the tro-
phoblast $[65]$

$>\quad$ The presence of IL- 1 in the embryo culture medium has been correlated with successful implantation after in vitro fertilization [69]
Studies in mice

$>\quad$ IL-1 $\beta$ and IL-1R tI are present in the uterus at the time of implantation [70]

$>$ IL-1 family components are present preimplantation mouse embryos at various developmental stages [66]

$>\quad$ Implantation in mice is prevented by administration with IL-1 Receptor antagonist [70] 
TNF-a) [68]. The importance of IL-1 in blastocyst implantation has been also supported by studies in in vitro fertilization and embryo transfer techniques [69]. Undoubtedly, the most important role of the IL-1 family in embryonic implantation has been revealed by in vivo studies in mice. Simón et al. [70] showed that intraperitoneal injection of an antagonist of IL- 1 biological activity (IL-1Ra) into pregnant mice prior to implantation caused implantation failure. Indeed, IL-1Ra interferes with embryonic attachment by a direct effect on the endometrial epithelium as a result of down-regulation of integrins $\alpha 4, \alpha \mathrm{v}$ and $\mathrm{b} 3$ [71]. Although all these studies support a fundamental role of the IL- 1 in successful reproduction, mice lacking the most important IL-1 family components, e.g. IL-1 $\beta$ or IL-1R tI genes, breed normally with only a slight reduction in mean litter size $[72,73]$.

In order to clarify the role of IL-1 in materno-fetal immune-tolerance, we performed studies in animal species characterized by different reproductive strategies.

\section{STUDIES ON IL-1 IN SQUAMATE REPTILES AND ELASMOBRANCH FISHES}

Our study on different species of vertebrates is based on the hypothesis that biological mechanisms allowing materno-fetal immunotolerance had to be developed since viviparity was established [74]. We also speculated that similar biological mechanisms also had to be present in species with internal fertilization even if the embryo does not grow in the maternal tissues [75]. In these species that lay fertilized eggs in the external environment (oviparity), a more or less prolonged phase of embryonic development can take place in the mother's tissues before egg laying. As in viviparity, the female reproductive tissues of species with oviparity are necessarily exposed to paternal-derived antigens, first on the sperm and then on the zygote/embryo.

We began the so-termed "evolutionary studies" within a collaboration with Prof. G. Ghiara (Figure $6 \mathrm{~A})$, soon after he became a member of the Faculty of Sciences at the University of Siena (Italy) in the early 90s. I learned from him for the first time that some species of squamate reptiles were characterized by a placental viviparity. By means of his collaborators from the University of Naples, we were able to get the placenta of a squamate reptile of the family Scincidae, the three-toed skink Chalcides chalcides [76] (Figure 6B). Like other squamates, $C$. chalcides has a very specialized epithelio-chorial placenta with morphological and functional similarities to the one found in many therian mammals [76-79]. In this type of placenta, the chorion forms very high ridges that interdigitate with corresponding ridges of the uterine mucosa [76, 77] (Figure 6C).

We examined this type of placenta for expression of IL- 1 and found that, similarly to mammals, IL- 1 was present at the materno-fetal interface both in the chorion and in the maternal uterus [80]. Furthermore, as IL- 1 is an essential molecule for blastocyst implantation in mammals [63-66, 70], we performed studies also in the uterus of $C$. chalcides at the pre-vitellogenic and vitellogenic stages. These studies revealed that, IL$1 \beta$ and IL-1R tI are expressed in reproductive tissues of $C$. chalcides at the peri-implantation time and pregnancy [80, 81].

To further verify the importance of IL-1 in nonmammalian placental vertebrates, we later studied the placenta of a cartilaginous fish, the smoothhound shark Mustelus canis [82] (Figure 7). The placenta forms in this species [10] at approximately mid-gestation, in conjunction with yolk store depletion, and persists until
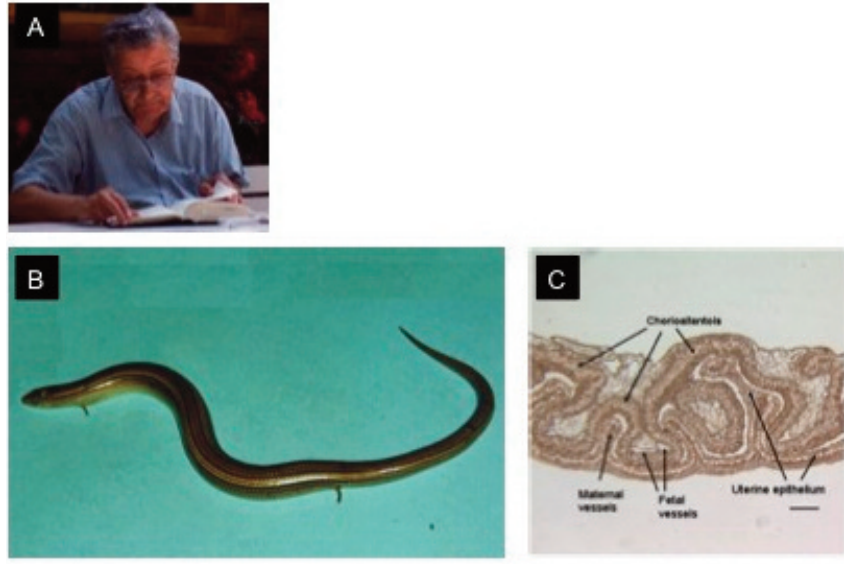

Figure 6. A. Prof. Gianfranco Ghiara (1922-2007); B. The three-toed skink Chalcides chalcides. C. The chorio-allantoic placenta of Chalcides chalcides.

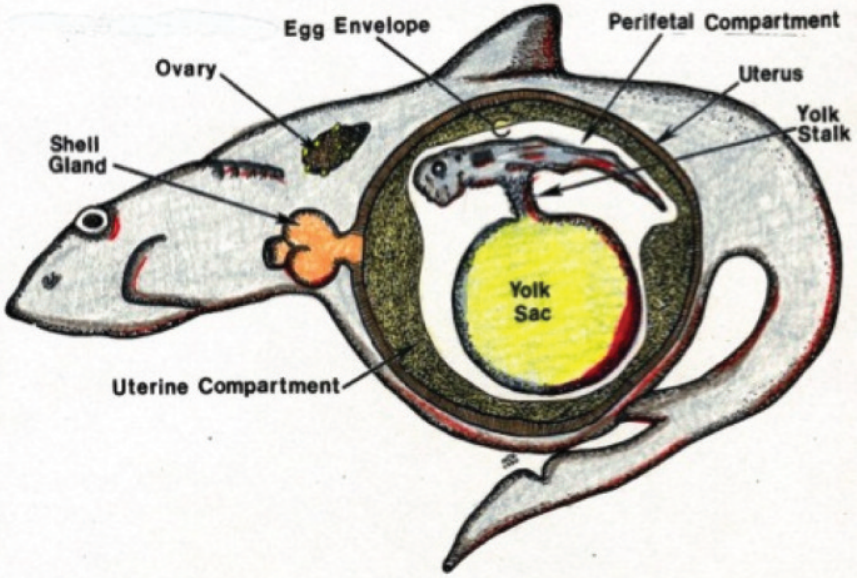

Figure 7. The smoothhound shark Mustelus canis. 
term. This study was made possible thanks to the collaboration with Prof. W. C. Hamlett, from Indiana University School of Medicine, Notre Dame, Indiana (USA).

We then wondered whether IL-1 was a cytokine involved in placental viviparity or it could be involved also in viviparity without the formation of a true placenta or even in oviparity. We were able to answer all these questions thanks to collaboration with French scientists, Dr. B. Heulin and Dr. C. P. Guillaume who brought us specimen of Lacerta vivipara, a species which exhibits reproductive bimodality, i.e. the coexistence of viviparous and oviparous populations depending on the habitat [83] . Viviparity in this species is characterized by a very simple type of chorioallantoic placenta in which the chorioallantois is juxtaposed to the uterine lining, with the eggshell interposed between them throughout gestation [8]. Oviparity is characterized by embryo/egg retention until stage 30-35 in oviparity [84].

The studies revealed that IL-1 family components were expressed in the female reproductive tissues of both the oviparous and viviparous species [85] supporting that immunological mechanisms mediated by cytokines are required in species in which maternal tissues must deal with exposure to paternal antigen-bearing cells i.e. sperm and embryo.

On the whole, the studies in squamate reptiles and fishes led us to speculate that secretion and/or action of cytokines at the materno-fetal interface represents a form of adaptation toward tolerance of paternal antigen-bearing cells.

\section{STUDIES IN AMPHIBIANS}

In addition to oviparity and viviparity, amphibians and fishes include species with external fertilization, a reproductive strategy named ovuliparity. In these species, the eggs are released from the female reproductive tract and their fertilization and embryonic development take place in the external environment. Thus, there is no contact at all between embryonic antigens and maternal tissues and species presenting ovuliparity, can be considered natural negative controls in studies on materno-fetal immunotolerance.

By a collaboration with Prof. R. Brizzi, from the University of Florence (Italy) we were been able to compare viviparity with oviparity and ovuliparity in amphibians. The species selected were: the viviparous Salamandra lanzai, the oviparous Triturus carnifex and the ovuliparous Bufo bufo (Figure 8).

The data obtained showed that, although at a much lower degree in respect to viviparity/oviparity, expression of IL- $1 \beta$ and IL-1R t 1 , was present in ovuliparity as well [86]. At first these data appeared to contradict
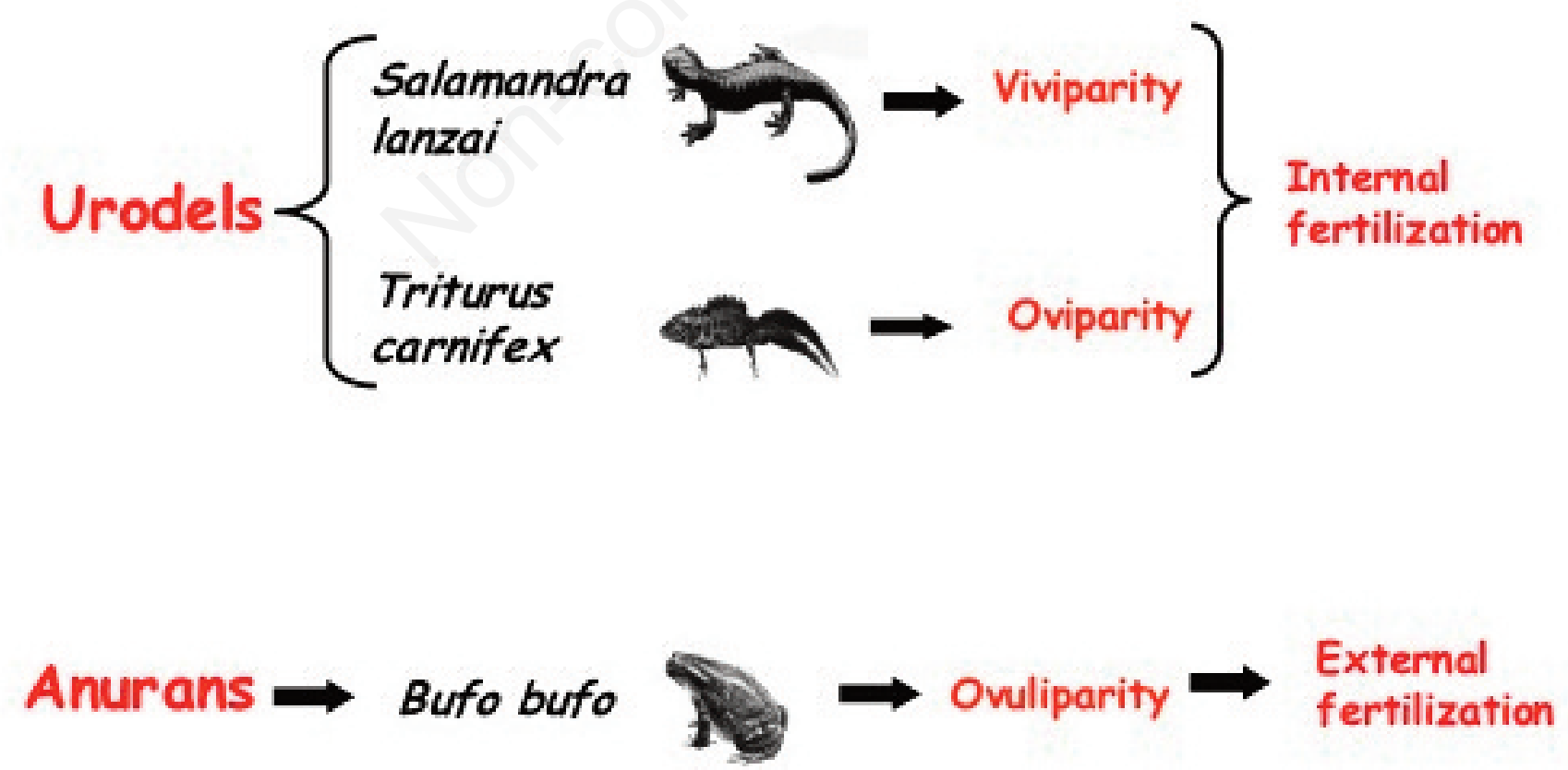

Figure 8. Species of amphibians with different reproductive strategies, viviparity, oviparity and ovuliparity. In Urodels, the eggs are fertilized in the female reproductive tissues and a more or less prolonged phase of embryonic development takes place in the mother's tissues. In Anurans, both the egg fertilization and embryo development occur in the external environment. 
the role of the IL-1 system in materno-fetal immunotolerance. As species not having the need of maternofetal immunotolerance, ovuliparous species were indeed thought not to express IL- 1 in the female reproductive tissues. However in the light of the role of IL1 in the innate immunity, these studies provided a new understanding of the expression of IL-1 components in the female reproductive tissues. In every species in fact, apart from their reproductive strategy, the mucosa of the female reproductive tract interfaces with a lumen exposed to an extensive variety of both commensal and pathogenic microbes coming from the external environment. To control the bacterial antigenic load, the mucosal epithelium of the female reproductive tract, develops defense mechanisms mainly based on the expression of TLRs [87-89]. Given the high homology of TLRs and IL-1R, a basic expression of IL- 1 and IL-1R $\mathrm{t} l$ in the female reproductive mucosa can be considered an immune mechanism for host's protection against the attack of pathogens. This was confirmed by a spatial distribution of IL-1 components in the female reproductive tract of an ovuliparous species, Xenopous laevis, with a general increase toward the external environment [90].

Besides the important role of IL-1 in the protection against infection, IL- 1 response in the female reproductive tract of viviparous and in some extent in oviparous species has to contribute to maternal tolerance versus the paternal-derived antigens present on sperm, fertilized eggs, and embryo. The data in amphibians, which show increasing expression of IL-1 components, from ovuliparity to oviparity and viviparity appear to sup- port the above hypothesis leading us to propose that an enhancement of the innate immunity in the female reproductive mucosa is an important biological mechanism in the materno-fetal immunotolerance (a schematic representation of the IL-1 response in species with different reproductive strategies is shown in Figure 9).

\section{CONCLUSIONS}

Studies in humans showed that a) the trophoblast does not hide its diversity, but reveals itself by showing its less aggressive features; b) the maternal immune system in the uterus/decidua recognizes fetal trophoblast and interact with it; c) a proper molecular materno-fetal dialogue is fundamental for the success of pregnancy.

Studies in non-mammalian vertebrates revealed that an increase in the innate immune response in the female reproductive tissues occurs in species having the need of maternal immunotolerance versus the paternal-derived antigens on sperm and zygote/ embryo.

It can be concluded that, although non-mammalian vertebrates are far from mammals, they appear to represent a good model to understand the role of cytokines in materno-fetal immunotolerance.

\section{Future perspectives:}

Determination of the molecular mechanisms that allow fetal growth and survival in the maternal tissues might be useful to:

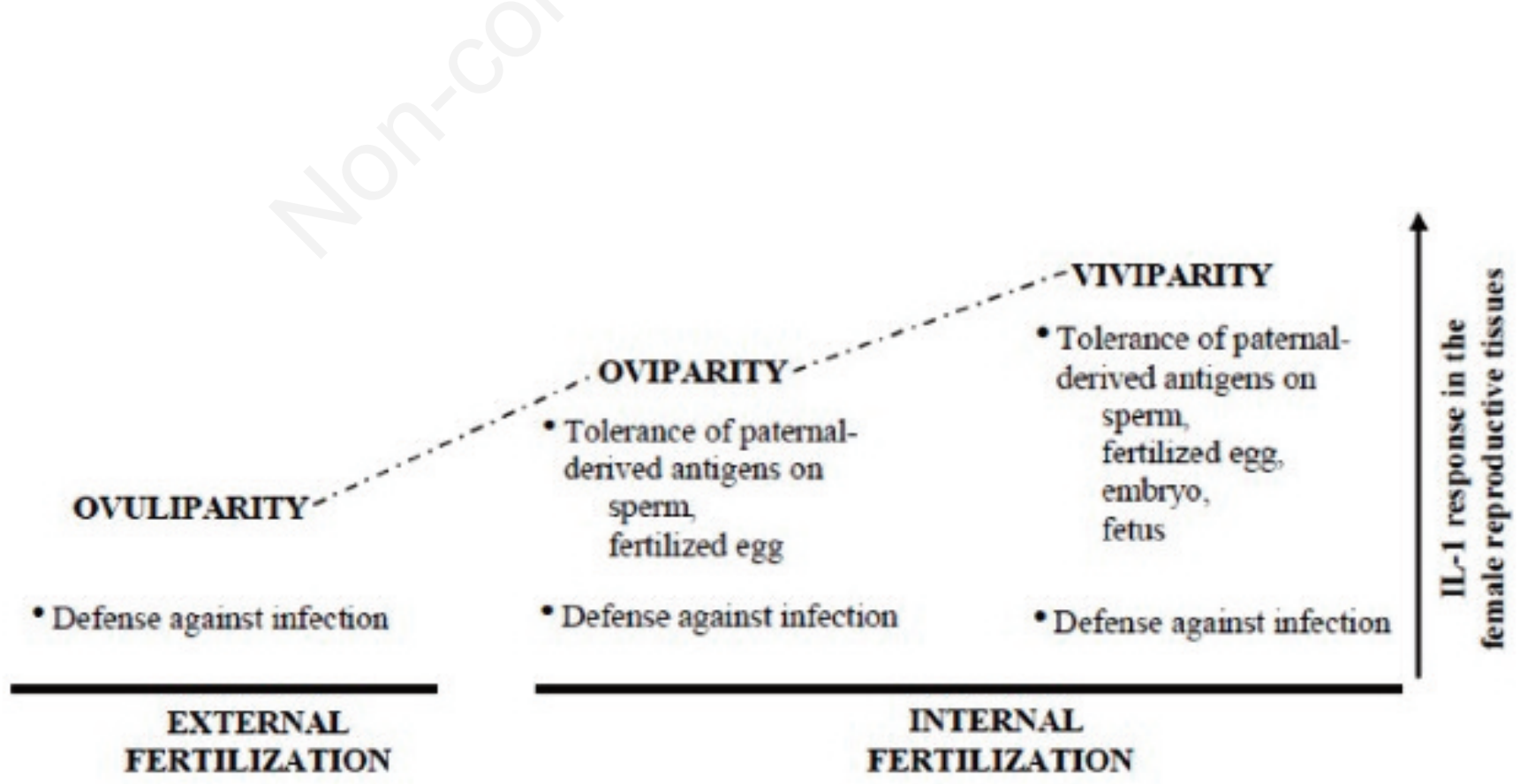

Figure 9. Enhancement of IL-1 expression in the female reproductive tissues from Ovuliparity to Oviparity and Viviparity in response to the increasing needs. 
develop new strategies for the treatment of infertility in humans;

develop new contraceptives;

develop new therapeutic interventions to prevent miscarriage or other pregnancy disorders such as preeclampsia and fetal growth retardation;

develop new strategies for improving the success of assisted reproduction;

\section{Some personal considerations}

The multiple biological mechanisms of materno-fetal immunotolerance arise in me some theoretical considerations that may be useful for human Society:

The materno-fetal tolerance accepts the difference and specificity of the other;

The materno-fetal tolerance recognizes the interdependence existing between the parties;

A correct dialogue is at the basis of the harmony among strangers;

The materno-fetal tolerance is a model of coexistence in human society.

\section{ACKNOWLEDGMENTS}

Special thanks to young scientists, Dr. Francesca Ietta and Roberta Romagnoli and Silke Jantra, who much contributed to the researches performed in our laboratory of Physiology of Reproduction, to my friend Elisa Bigliardi, Prof. of Zoology of the University of Siena (Italy), for her valuable help in conducting "evolutionary studies", to Dr. Chiara Mannelli for designing the picture of the fetus and to Prof. Antonella Bartoli for linguistic revision of the manuscript.

\section{REFERENCES}

1. Medawar PB. Some immunological and endocrinological problems raised by the evolution of viviparity in vertebrates. Symp Soc Exp Biol 1953;7:81-5.

2. Billington WD. The immunological problem of pregnancy: 50 years with the hope of progress. A tribute to Peter Medawar. J Reprod Immunol 2003;60:1-11.

3. Haig D. Genetic conflicts in human pregnancy. Q Rev Biol 1993;68: 495-532.

4. Paulesu L, Jantra $S$, Ietta, $F$, et al. Interleukin-1 in reproductive strategies. Evol Dev 2008;10:778-88.

5. Amoroso EC. Placentation. In: Parkers AS, ed. Marshall's physiology of reproduction. Vol 2. 3rd ed. London: Longmans Green; 1952. pp 127-311.

6. Crespi B, Semeniuk C. Parent-offspring conflict in the evolution of vertebrate reproductive mode. Am Nat 2004;163:635-53.

7. Dantzer, V. Epitheliochorial placentation. In: Knobil E, Neill JD, eds. Encyclopedia of Reproduction. London: Academic Press; 1999. pp 18-28.

8. Blackburn DG. Chorioallantoic placentation in squamate reptiles: structure, function, development and evolution. J Exp Zool 1993;266:414-30.

9. Stewart JR, Thompson MB. Evolution of placentation among squamate reptiles: recent research and future directions. Comp Biochem Physiol A Mol Integr Physiol 2000;127:411-31.
10. Hamlett WC, Eulitt AM, Jarrell RL, Kelly MA. Uterogestation and placentation in elasmobranchs. J Exp Zool 1993;266:347-67.

11. Dantzer V. Endotheliochorial placentation. In: Knobil E., Neill JD, eds. Encyclopedia of Reproduction. London: Academic Press; 1999. pp 1078-1084.

12. Budak E, Strauss JF III. Hemochorial placentation. In: Knobil E, Neill JD, eds. Encyclopedia of Reproduction. London: Academic Press; 1999. pp 603-606.

13. Huppertz B. The anatomy of the normal placenta. J Clin Pathol 2008;61:1296-302.

14. Taglauer ES, Wilkins-Haug L, Bianchi DW. Cell-free fetal DNA in the maternal circulation as an indication of placental health and disease. Placenta 2013 [In press].

15. Kovats K, Main EK, Libraci $C$, et al. A class I antigen HLA-G, expressed in human trophoblasts. Science 1990;248:220-3.

16. Apps R, Murphy SP, Fernando R, et al. Human leucocyte antigen (HLA) expression of primary trophoblast cells and placental cell lines, determined using single antigen beads to characterize allotype specificities of anti-HLA antibodies. Immunology 2009;127:26-39.

17. Apps R, Gardner L, Moffett A. A critical look at HLA-G. Trends Immunol 2008;29:313-21.

18. Ober C, Aldrich C, Rosinsky B, et al. HLA-G1 protein expression is not essential for fetal survival. Placenta 1998;19:127-32.

19. Ishitani $N$, Sageshima $N$, Hatake K. The involvement of HLA-E and $-F$ in pregnancy. J Reprod Immunol 2006;69:101-13.

20. Moffett-King A. Natural killer cells and pregnancy. Nat Rev Immunol 2002;2:656-63.

21. Hiby SE, Apps R, Sharkey AM, et al. Maternal activating KIRs protect against human reproductive failure mediated by fetal HLA-C2. J Clin Invest 2010;120:4102-10.

22. Hemberger MJ. Immune balance at the foeto-maternal interface as the fulcrum of reproductive success. Reprod Immunol 2013;97:36-42.

23. Wood KJ, Sakaguchi S. Regulatory T cells in transplantation tolerance. Nat Rev Immunol 2003;3:199-210.

24. Sakaguchi S. Naturally arising CD4+ regulatory $T$ cells for immunologic self-tolerance and negative control of immune responses. Annu Rev Immunol 2004;22:531-62.

25. Saito $S$, Nishikawa K, Morii T, et al. Expression of activation antigens CD69, HLA-DR, interleukin-2 receptor-alpha (IL-2Ra) and $I L-2 R b$ on $T$ cells of human decidua at an early stage of pregnancy. Immunology 1992;75:710-2.

26. Darrasse-Jeze G, Klatzmann D, Charlotte F, et al. CD4+CD25+ regulatory/suppressor T cells prevent allogeneic fetus rejection in mice. Immunol Lett 2006;102:106-9.

27. Kim JM, Rasmussen JP, Rudensky A. Regulatory T cells prevent catastrophic autoimmunity throughout the lifespan of mice. Nat Immunol 2007;8:191-7.

28. Sasaki Y, Sakai M, Miyazaki S, et al. Decidual and peripheral blood $C D 4+C D 25+$ regulatory $T$ cells in early pregnancy subjects and spontaneous abortion. Mol Hum Reprod 2004;10:347-53.

29. Fallarino $F$, Grohmann $U$, Hwang $K W$, et al. Modulation of tryptophan catabolism by regulatory T cells. Nat Immunol 2003;4: 1206-12.

30. Christiansen OB. Reproductive immunology. Mol Immunol 2013;55:8-15.

31. Makrigiannakis A, Karamouti M, Drakakis P, et al. Fetomaternal immunotolerance. Am J Reprod Immunol 2008;60:482-96.

32. Oreshkova T, Dimitrov R, Mourdjeva MA. Cross-talk of decidual stromal cells, trophoblast, and immune cells: a prerequisite for the success of pregnancy. Am J Reprod Immunol 2012;68:366-73.

33. Paulesu L, Bhattacharjee J, Bechi N, et al. Pro-inflammatory cytokines in animal and human gestation. Curr Pharm Des 2010;16:3601-15.

34. Chaouat $G$, Dubanchet $S$, Ledée $N$. Cytokines: important for implantation? J Assist Reprod Genet 2007;24:491-505. 
35. Cameo P, Srisuparp S, Strakova Z, Fazleabas AT. Chorionic gonadotropin and uterine dialogue in the primate. Reprod Biol Endocrinol 2004;2:50.

36. Eskandar MA, Al-Shahrani M, Shaamash A, et al. Early maternal serum $\beta$-human chorionic gonadotropin measurements after ICSI in the prediction of long-term pregnancy outcomes: a retrospective cohort analysis. J Clin Med Res 2011;3:30-5.

37. Shapiro BS, Daneshmand ST, Restrepo H, Garner FC. Serum hCG measured in the peri-implantation period predicts IVF cycle outcome. Reprod Bio Med 2012;25:248-53.

38. Schäfer-Somi S. Cytokines during early pregnancy of mammals: a review. Anim Reprod Sci 2003;75:73-94.

39. Saito S. Cytokine network at the feto-maternal interface. J Reprod Immunol 2000;47:87-103.

40. Vilcek J, Le J. Immunology of cytokines: an introduction. In: Thomson A, ed. The Cytokine handbook. London: Academic Press; 1994. pp 1-19.

41. Saito S. Cytokine cross-talk between mother and the embryolplacenta. J Reprod Immunol 2001;52:15-33.

42. Paria BC, Reese J, Das SK, Dey SK. Deciphering the cross-talk of implantation: advances and challenges. Science 2002;296:2185-8.

43. Moffett $A$, Loke C. Immunology of placentation in eutherian mammals. Nat Rev Immunol 2006;6:584-94.

44. Wegmann TG, Lin H, Guilbert L, Mosmann TR. Bidirectional cytokine interactions in the maternal-fetal relationship: is successful pregnancy a TH2 phenomenon? Immunol Today 1993;14:353-66.

45. Chaouat $G$, Zourbas $S$, Ostojic $S$, et al. A brief review of recent data on some cytokine expressions at the materno-foetal interface which might challenge the classical Th1/Th2 dichotomy. J Reprod Immunol 2002;53:241-56.

46. Dekel N, Gnainsky Y, Granot I, Mor G. Inflammation and implantation. Am J Reprod Immunol 2010;63:17-21.

47. Zourbas S, Dubanchet S, Martal J, Chaouat, G. Localization of proinflammatory (IL-12,IL-15) and anti-inflammatory (IL-11, IL13) cytokines at the foetomaternal interface during murine pregnancy. Clin Exp Immunol 2001;126:519-28.

48. Koga K, Aldo PB, Mor GJ. Toll-like receptors and pregnancy: trophoblast as modulators of the immune response. Obstet Gynaecol Res 2009;35:191-202.

49. Stewart CL, Kaspar P, Brunet LJ, et al. Blastocyst implantation depends on maternal expression of leukaemia inhibitory factor. $\mathrm{Na}$ ture 1992;359:76-9.

50. Robb L, Li R, Hartley L, et al. Infertility in female mice lacking the receptor for interleukin 11 is due to a defective uterine response to implantation. Nat Med 1998;4:303-8.

51. White CA, Robb L, Salamonsen LA. Uterine extracellular matrix components are altered during defective decidualization in interleukin-11 receptor alpha deficient mice. Reprod Biol Endocrinol 2004;2:76.

52. Heinrich PC, Behrmann I, Müller-Newen G, et al. Interleukin-6type cytokine signalling through the gp130/Jak/STAT pathway. Biochem J 1998;334:297-314.

53. Paulesu L, Romagnoli R, Bigliardi E. Materno-fetal immunotolerance: is interleukin-1 a fundamental mediator in placental viviparity? Dev Comp Immunol 2005;29:409-15.

54. Paulesu L, Jantra $S$, Ietta $F$, et al. Interleukin-1 in reproductive strategies. Evol Dev 2008;10:778-88.

55. Bird S, Zou J, Wang T, et al. Evolution of interleukin-1ß. Cytokine Growth Factor Rev 2002;13:483-502.

56. Roach JC, Glusman G, Rowen L, et al. The evolution of vertebrate Toll-like receptors. Proc Natl Acad Sci USA 2005;102: 9577-82.

57. Ishii A, Kawasaki M, Matsumoto $M$, et al. Phylogenetic and expression analysis of amphibian Xenopus Toll-like receptors. Immunogenetics 2007;59:281-93.
58. Purcell MK, Smith KD, Hood L, et al. Conservation of Toll-like receptor signalling pathways in Teleost fish. Comp Biochem Physiol D Genomics Proteomics 2006;1:77-88.

59. Medzhitov R, Preston-Hurlburt P, Janeway CA. A human homologue of the Drosophila Toll protein signals activation of adaptive immunity. Nature 1997;388:394-7.

60. Rock FL, Hardiman G, Timans JC, et al. A family of human receptors structurally related to Drosophila Toll. Proc Natl Acad Sci USA 1998;95:588-93.

61. O'Neill LA, Greene C. Signal transduction pathways activated by the IL-1 receptor family: ancient signalling machinery in mammals, insects, and plants. J Leukoc Biol 1998;63:650-7.

62. Hoffmann JA, Reichhart JM. Drosophila innate immunity: an evolutionary perspective. Nat Immunol 2002;3:121-6.

63. Kauma S, Matt D, Strom S, et al. Interleukin-1 beta, human leukocyte antigen HLA-DR alpha, and transforming growth factor-beta expression in endometrium, placenta, and placental membranes. Am J Obstet Gynecol 1990;163:1430-7.

64. Simón C, Piquette GN, Frances A, Polan ML. Localization of Interleukin-1 type I receptor and Interleukin-1 beta in human endometrium throughout the menstrual cycle. J Clin Endocrinol Metab 1993;77:549-55.

65. Paulesu L, King A, Loke YW, et al. Immunohistochemical localization of IL-1 alpha and IL-1 beta in normal human placenta. Lymphokine Cytokine Res 1991;10:443-8.

66. Krüssel JS, Simón C, Rubio MC, et al. Expression of interleukin-1 system mRNA in single blastomeres from human preimplantation embryos. Hum Reprod 1998;13:2206-11.

67. Masuhiro K, Matsuzaki N, Nishino E, et al. Trophoblast-derived interleukin-1 (IL-1) stimulates the release of human chorionic gonadotropin by activating $I L-6$ and $I L-6$ receptor system in first trimester human trophoblasts. J Clin Endocrinol Metab 1991;72: 594-601.

68. Minas V, Loutradis D, Makrigiannakis A. Factors controlling blastocyst implantation. Reprod Biomed Online 2005;10:205-16.

69. Karagouni EE, Chryssikopoulos A, Mantzavinos T, et al. Interleukin-1beta and interleukin-1alpha may affect the implantation rate of patients undergoing in vitro fertilization-embryo transfer. Fertil Steril 1998;70:553-9.

70. Simón C, Frances A, Piquett GN, et al. Embryonic implantation in mice is blocked by interleukin-1 receptor antagonist. Endocrinology 1994;134:521-8.

71. Simón C, Valbuena D, Krüssel J, et al. Interleukin-1 receptor antagonist prevents embryonic implantation by a direct effect on the endometrial epithelium. Fertil Steril 1998;70:896-906.

72. Horai $R$, Asano M, Sudo K, et al. Production of mice deficient in genes for interleukin (IL)- $1 \alpha$, IL- $1 \beta$, IL- $1 \alpha / \beta$, and IL-1 receptor antagonist shows that $I L-1 \beta$ is crucial in turpentine-induced fever development and glucocorticoid secretion. J Exp Med 1998;187: 1463-75.

73. Abbondanzo SJ, Cullinan EB, McIntyre $K$, et al. Reproduction in mice lacking a functional type I IL-1 receptor. Endocrinology 1996; 137:3598-601.

74. Paulesu L, Romagnoli R, Bigliardi E. Materno-fetal immunotolerance: is Interleukin-1 a fundamental mediator in placental viviparity? Dev Comp Immunol 2005;29:409-15.

75. Paulesu L, Jantra $S$, Ietta $F$, et al. Interleukin-1 in reproductive strategies. Evol Dev 2008;10:778-88.

76. Ghiara G, Angelini F, Gerani M, et al. Evolution of viviparity in Scincidae (Reptilia, Lacertilia). Acta embryologiae et morphologiae experimentalis. Nova Serie 1987;8:187-201.

77. Blackburn DG. Histology of the late-stage placentae in the matrotrophic skink Chalcides chalcides (Lacertilia; Scincidae). J Morphol 1993;216:179-95. 
78. Paulesu L, Cateni C, Romagnoli R, et al. Evidence of $H$ beta 58, a gene involved in mammalian placental development, in the threetoed skink, Chalcides chalcides (Squamata: Scincidae), a viviparous placentotrophic reptile. Placenta 2001;22:735-41.

79. Jones CJ, Cateni C, Guarino FM, Paulesu LR. Glycosylation of the materno-foetal interface in the pregnant viviparous placentotrophic lizard Chalcides chalcides: a lectin histochemical study. Placenta 2003;24:489-500.

80. Paulesu L, Romagnoli $R$, Marchetti $M$, et al. Cytokines in the viviparous reproduction of squamate reptiles: interleukin-1 alpha (IL1 alpha) and IL1 beta in placental structures of a skink. Placenta 1995;16:193-205.

81. Romagnoli R, Cateni C, Guarino FM, et al. Potential role of interleukin-1 at the peri-ovulation stage in a species of placental viviparous reptile, the three-toed skink, Chalcides chalcides (Squamata: Scincidae). Reprod Biol Endocrinol 2003;1:60.

82. Cateni C, Paulesu L, Bigliardi E, Hamlett WC. The interleukin 1 (IL-1) system in the uteroplacental complex of a cartilaginous fish, the smoothhound shark, Mustelus canis. Reprod Biol Endocrinol 2003;1:25.

83. Heulin B, Osenegg K, Michel D. Demography of a bimodal reproductive species of lizard (Lacerta vivipara): survival and density characteristics of oviparous populations. Herpetologica 1997;53: 432-44.
84. Heulin B, Osenegg K, Lebouvier, M. Timing of embryonic development and birth dates in oviparous and viviparous strains of Lacerta vivipara: testing the predictions of an evolutionary hypothesis. Port Acta Biol Ser B 1991;12:517-28.

85. Paulesu L, Bigliardi E, Paccagnini E, et al. Cytokines in the oviparity/viviparity transition: evidence of the interleukin-1 system in a species with reproductive bimodality, the lizard Lacerta vivipara. Evol Dev 2005;7:282-8.

86. Jantra S, Bigliardi E, Brizzi R, et al. Interleukin 1 in oviductal tissues of viviparous, oviparous, and ovuliparous species of amphibians. Biol Reprod 2007;76:1009-15.

87. Wira CR, Fahey JV, Sentman CL, et al. Innate and adaptive immunity in female genital tract: cellular responses and interactions. Immunol Rev 2005;206:306-35.

88. Quayle AJ. The innate and early immune response to pathogen challenge in the female genital tract and the pivotal role of epithelial cells. J Reprod Immunol 2002;57:61-79.

89. Fahey JV, Schaefer TM, Channon JY, Wira CR. Secretion of cytokines and chemokines by polarized human epithelial cells from the female reproductive tract. Hum Reprod 2005;20:1439-46.

90. Jantra S, Paulesu L, Lo Valvo M, et al. Cytokine components and mucosal immunity in the oviduct of Xenopus laevis (amphibia, pipidae). Gen Endocrinol 2011;173:454-60. 